Original Research Article

\title{
A Critical Discourse Analysis on Teachers' Verbal Feedback Patterns in EFL CLT Classrooms
}

Asma Dabiri

Shiraz University of Medical Sciences, Shiraz, Fars, Iran

School of Paramedical Sciences, Opposite Homa Hotel, Meshkinfam St., Shiraz, Iran.

P.O. Box: 71439-14693

Article History:

Submitted: $13^{\text {th }}$ December 2017, Accepted: $12^{\text {th }}$ June 2018, Published: $15^{\text {th }}$ October 2018

\begin{abstract}
As providing feedback can have an effective role for the learning process, this study with a critical discourse analysis point of view in social scientific research investigated feedback patterns of four English language teachers on learners' responses in four English Language institutes with Communicative Language Teaching (CLT) approach toward teaching and learning. In doing so, the classes were observed. The interactions were audio-taped and transcribed. The findings revealed that in providing feedback to learners, teachers gave positive feedback (approving and repetition), interactional feedback and corrective (negative feedback) in classrooms. Positive feedback as approving and repetition were the most type of feedback which the teachers made use of. The findings provide insights into feedback patterns in an EFL context and consequently they set up an argument to critically assess one of the most fundamental principles of CLT approach which is giving positive feedback to learners. Attention should be directed to EFL teachers' ideologies in providing feedback to the students to uncover their philosophy of teaching and learning as a clue to detect their criteria in choosing some habits of providing feedback than others and hence to expand this area further.

Keywords: Critical discourse analysis, English as a foreign language context, verbal feedback pattern
\end{abstract}

HOW TO CITE: Dabiri, A. (2018). A Critical Discourse Analysis on Teachers' Verbal Feedback Patterns in EFL CLT Classrooms. JEES (Journal of English Educators Society), 3 (2), 129-140. doi: https://doi.org/10.21070/jees.v3i2.1262

\section{Introduction}

The EFL classroom is more or less the only opportunity for language learners to communicate and use English. Investigating classroom discourse can give insight on what goes on in the process of giving feedback which is important in students' progress. Related studies

E-mail address: dabiri asma@yahoo.com

Peer reviewed under reponsibility of Universitas Muhammadiyah Sidoarjo.

(C) 2018 Universitas Muhammadiyah Sidoarjo, All right reserved, This is an open access article under

the CC BY license (http://creativecommons.org/licenses/by/4.0/) 
indicated that even though in the literature, there were ample definitions and classifications in terms of feedback types, studies on verbal or immediate feedback in classrooms were inadequate to perceive what patterns were actually implemented (Evans, 2013; Flores, Simao, Baros \& Pereira, 2015; Han \& Hyland, 2015; Vermunt \& Donche, 2017). Subsequently, this study would be a further attempt with a critical discourse analysis point of view in order to shed light on this issue. Since what goes on in classroom discourse manifest one aspect of social life, CDA (critical discourse analysis) in social scientific research contributes to address this problem by analyzing the potential sources, and possibilities of overcoming them. So, the aim of this study was to investigate the feedback patterns of four EFL English language teachers who taught advanced levels in four English Language institutes with a CLT approach as a case study in an EFL context in Iranian CLT classrooms.

There were a number of definitions with regard to the term feedback in the literature of teaching and learning languages (Le, 2010). Mainly it was defined as let learners know about the quality of their actions in the process of learning. To further define it, giving feedback gave an idea about learners' errors and directs them to improve (Lewis, 2002; Vermunt \& Donche, 2017). Evans (2013) categorized it like saying something was accurate or inaccurate, praising, modifying a student's answer, repeating, summarizing and criticizing.

Feedback can be categorized as positive or negative. Positive feedback is the verification of the correct answer. Positive feedback was significant as it functioned as an affective support to the learner and created motivation (Ellis, 2009; Le, 2010). Not only can they serve as complements but also as preface to subsequent correction or modification. Teachers using this type of feedback would say words or phrases to point out that the learner's response is all right. In most instances, the common words are 'good', 'very good', 'yes', 'correct' , 'ok' and 'well done'. Negative feedback intended to correction of learners' errors (Han \& Hyland, 2015). Of course, several scholars have classified negative feedback as, for example, corrective feedback. Corrective feedback was further defined as recasts, elicitation, meta-linguistic cues, clarification requests and repetitions (Flores, Simao, Barons, \& Pereira, 2015). As (Evans, 2013) suggested, the "repetition of a speaker's utterance can be either a negative or a positive nature".

In the literature, there are other classifications like (Sinclair \& Coulthard, 1992) study that mentioned another category for feedback as the "evaluative feedback" in the classroom discourse which included the acts of accepting, evaluating and commenting. Or like 
"interactional feedback" which was defined as a strategy to expand or revise a student's answer (Han \& Hyland, 2015).

Giving Feedback should be purposeful in nature. Vermunt \& Donche (2017) proposed that not only should feedback concentrated on what students did mistakenly, but also to improve future activities. According to (Boud, 2000), "A good feedback is given without personal judgment or opinion, given based on facts, always neutral and objective, constructive and focus on the future" (p. 7).

Feedback quality is also important to reflect on. For example, Herschell, Greco, Filcheck, $\&$ McNeil (2002) advised that feedbacks should be designed rather than random and broad. Flores et al. (2015) explained that feedbacks should be outcome-focused and encouraging as well. Evans (2013) gives further details about teachers' feedback that “often lacks thought or depth; students often misunderstand their teachers' feedback... and many students do not attend to teachers' feedback to begin with!” (p. 1). (Han \& Hyland, 2015) also revealed that most forms of feedback were not comprehended by students.

Even though there were a variety of feedback types which the teacher benefited, what was important was the appropriate choice of feedback on the basis of students' needs and instructional activities (Konold, K.E., Miller, S.P., \& Konold, 2004). Attending to these forms of feedback would help teachers to provide positive outcomes from their students and consequently to meet the instructional goals of learning.

One can find out in the related literature ample definitions and classifications in terms of feedback types but as it can be established; studies on verbal or immediate feedback in classrooms are inadequate to perceive what patterns are actually implemented by teachers in giving feedback to learners (Evans, 2013; Flores et al., 2015; Han \& Hyland, 2015; Vermunt $\&$ Donche, 2017). So, this study elaborated on this uncovered area; the feedback patterns of four EFL English language teachers who taught advanced levels in four English Language institutes as a case study in an EFL context in Iranian CLT classrooms. Accordingly, the following questions were posed in this study:

1. What patterns of feedback are employed by English teachers in an EFL context?

2. Which pattern of feedback is most frequently employed by English teachers? 


\section{Methods}

\subsection{Participants}

The study was conducted in four English language institutes which had a communicative language teaching (CLT) approach toward teaching and learning. The participants were four female English language teachers, who had teaching experience between five to seven years. Purposive sampling procedure was used to select the participants; they were certified by their managers as experienced teachers in practicing CLT.

\subsection{Instruments}

The researcher observed the teachers while teaching in the classroom for one session, approximately forty-five minutes. The interactions were audio-taped and transcribed for further analysis. The four participant of this study were each given a number: $1,2,3$, and 4 .

\subsection{Data Analysis}

The transcribed data were coded according to the type and frequency of the feedback patters which were observed in the classrooms. Then, (Fairclough, 1995) model of critical discourse analysis, which appeared in a collection of papers presenting a variety of 'methods' in CD (Wodak \& M, 2001), was used to analyze the data. The methodology can be organized in five 'stages':

Stage1 : Focus upon a social wrong, in its semiotic aspect

Stage 2: Identify obstacles to it being tackled, through analysis of

a. the network of practices it is located within

b. the relationship of semiosis to other elements within the particular practice(s) concerned the discourse ( the semiosis itself) has four analyses including structural, interactional, inter discursive, and linguistic and semiotic analysis.

Stage 3: Consider whether the social order (network of practices) in a sense 'needs' the problem Stage 4: Identify possible ways past the obstacles

Stage 5: Reflect critically on the analysis (1-4).

\section{Stage1: Focus upon a social wrong, in its semiotic aspect}

Social wrongs (problems) are aspects of social systems, forms or orders which are unfavorable to human well-being. They could be restructured if not eliminated, though perhaps only through major changes in the systems, forms or orders. 
- Step1: Selecting a research topic which relates to or points up a social wrong.

To be productively approached in a trans-disciplinary way with a particular focus on dialectical relations between semiotic and other moments (diverse elements brought together to constitute a social practice).

- Step2: Constructing objects of research for initially identified research topics by theorizing them in a trans-disciplinary way.

Constructing objects of research: drawing upon relevant bodies of theory in various disciplines to go beyond and beneath the obviousness of the topic.

In a trans-disciplinary way: either in research teams which bring together specialists in relevant disciplines or by engaging with literature in such disciplines. To work with the grain of various bodies of social theory and research.

\section{Stage 2: Identify obstacles to it being tackled}

- Step1: Analyzing dialectical relations between semiosis and other social elements: between orders of discourse and other elements of social practices, between texts and other elements of events.

- Step2: Selecting texts, and focuses and categories for their analysis, in the light of and appropriate to the constitution of the object of research.

- Step3: Carrying out analyses of texts; both inter discursive analysis and linguistic/semiotic analysis.

Textual analysis: includes both linguistic analysis and if relevant; analysis of other semiotic forms, such as visual images.

Inter-discursive analysis: analysis of which genres, discourses and styles are drawn upon and how they are articulated together.

\section{Stage 3: Considering whether the social order (network of practices) in a sense needs' the problem}

It leads us to consider whether the social wrong in focus is inherent to the social order, whether it can be addressed within it or only by changing it.

\section{Stage 4: Identify possible ways past the obstacles}

Creating a semiotic point of view entry into research on the ways in which these obstacles are actually tested, challenged and resisted, be it within organized political or social groups or movements or more informally by people in the course of their ordinary working, social and domestic lives. A specifically semiotic focus would include ways in which dominant discourse 
is reacted to, criticized and opposed in its argumentation, its construal of the world, its construal of social identities and so forth.

\section{Findings}

\subsection{Positive Feedback (Approving\& Repetition)}

Among the emerged feedback types were positive feedback (approving\& repetition) which the teachers made use of. Table1 presents the frequency of the positive feedback as the approving and repetition patterns.

Table 1. The Teachers' Frequency of Positive Feedback (Approving\& Repetition)

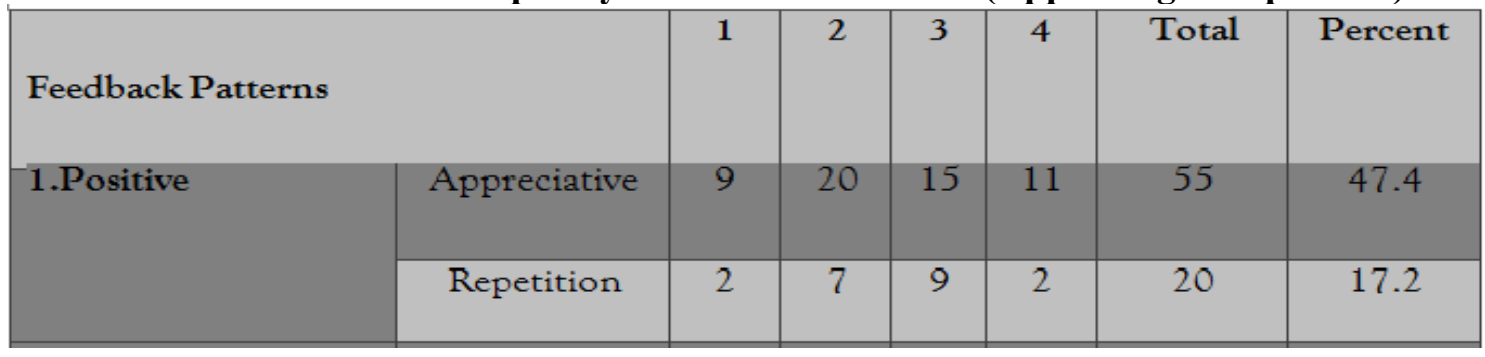

Positive feedback was observed as two patterns: approving and repetition. It was revealed that teachers frequently used two patterns: i) the teacher approving the students. ii) The teacher repeating the answers given by the students. Before the positive signs were provided, the teachers repeated the forms stated by the students to confirm the answers as well as to show interest in the content of the answer. The following extracts represent these patterns:

Example 1: (source/T1/Lines. 22-30)

$\mathrm{T}:[22]$ Ok... so, where does your sister work?

$\mathrm{T}:$ [23] your sister...where does she work?

S: [24] at bank.

$\mathrm{T}:[25]$ at a bank?

S: [26] at a bank.

$\mathrm{T}:$ [27] Where is the bank?

S: [28] In the town.

$\mathrm{T}:[29]$ In the town.

$\mathrm{T}:[30]$ Ok, well...good

\section{Example 2: (source/T4/Lines.105-117)}

$\mathrm{T}:[105]$ Ok, some fatty foods are meat and cheese, yes?

$\mathrm{T}:[106]$ any other fatty food that you know?

S: [107] Yes.

$\mathrm{T}:$ [108] Yes? 
S: [109] nuts.

$\mathrm{T}:[110]$ nuts.

S: [111]... (not clear)

S: [112] Teacher, potato chips.

$\mathrm{T}$ : [113] potato chips, yes, very good.

S: [114] butter?

$\mathrm{T}:[115]$ butter, yes, ok.

S: [116] ... (not clear)

$\mathrm{T}$ : [117] Ok, all these are fatty foods.

\subsection{Interactional Feedback}

Another revealed pattern of feedback was the interactional feedback which the teachers implemented in their classrooms. Table 2 shows the frequency of the interactional feedback manifested by the teachers.

Table 2. The Teachers' Frequency of Interactional Feedback

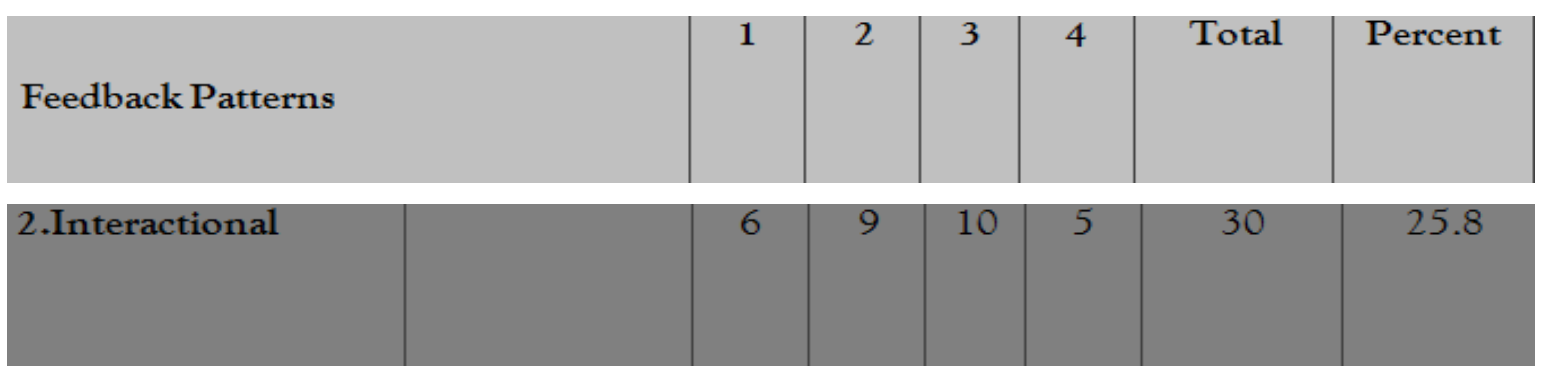

The teachers manifested this type of feedback as a policy to develop or improve a student's answer. In case, the student was uncertain to continue by responding with an incomplete answer, the teacher stated extended information to complete the student's utterance, to maintain the flow of interaction in the classroom. Following is an example of such feedback.

\section{Example 1: (source: /T2/ Lines 51-60.)}

$\mathrm{T}:$ [51] what did Sue do?

S: [52] She meet her friend

T: [53] Yes!

T: [54] Very good!

$\mathrm{T}:$ [55] she met her friend, right?

$\mathrm{T}:$ [56] And what did they do, then? 
S: [57] They... (Hesitation)

$\mathrm{T}:[58]$ Did they go to the park?

S: [59] No...(Hesitation)

$\mathrm{T}:[60]$ No. they went to the theater

\section{Example 2: (source: S/T3/Lines 44-50)}

$\mathrm{T}$ : [44] Ok, how the others?

T: [45] Anyone who travelled last summer?

S: [46] Yes.

T: [47] yes, then?

S: [48] In our area.

T: [49] Area? Yours, ok, ok, where?

S: [50] Margon.

\subsection{Corrective Feedback}

Teachers offered corrective or negative feedback to the students. Table 3 classifies the frequency of corrective feedback utilized by the teachers.

\section{Table 3. The Teachers' Frequency of the Corrective Feedback}

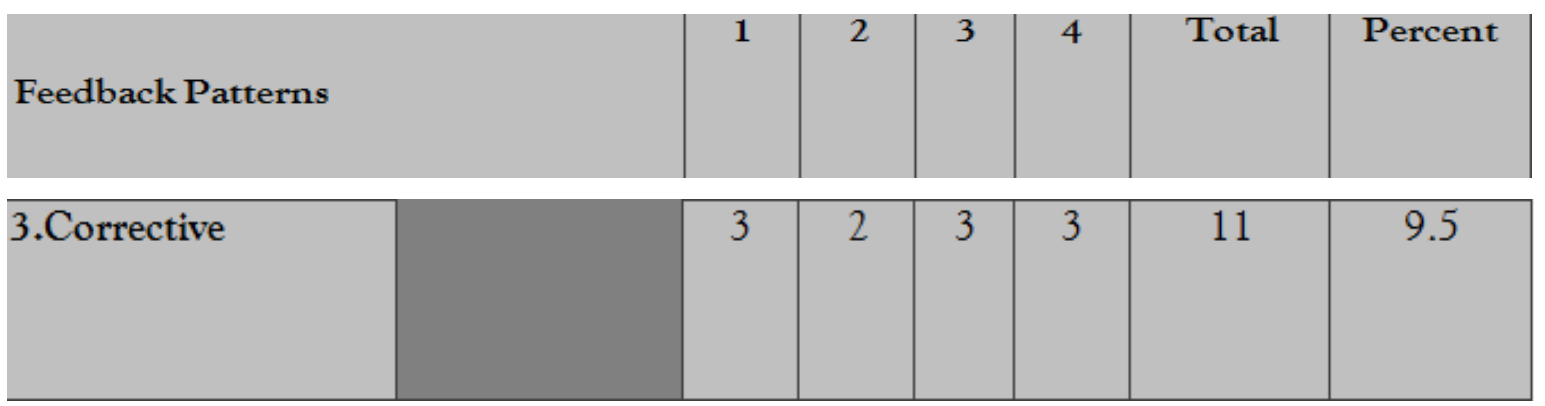

The teacher provided feedback on a student's utterance which consisted of an error. The feedback covered several forms: i) to specify the error, ii) to give the correct form, and iii) meta-linguistic information about the error. The following extracts exemplify this issue:

\section{Example 1: (S/T1/Lines 76- 87)}

T: [76] Ok, read loudly, please?

S: [77] (reading)

$\mathrm{T}:[78]$ occupation! (Correcting pronunciation)

S: [79] occupation, (Continue reading)

\section{Example 2:}

T: [80] restaurant, ok, Sara? (Correcting Pronunciation) 
S: [81] (not clear, very slow)

T: [82] Hmm?

S: [83] Big man... (Not clear, very slow)

T: [84] Big Man?!

S: [85] Fat man (very slow)

T: [86] Fat Man.

$\mathrm{T}$ : [87] Ok, all right, read it aloud so your friends can hear, all right?

Among feedback patterns that teachers made use of, it was revealed that teachers frequently used positive feedback as two patterns: i) the teacher approving the students. ii) The teacher repeating the answers given by the students. These patterns were in line with Sinclair \& Coulthard (1992) "evaluative feedback" that can be applicable to classroom's discourse which included the acts of accepting, evaluating and commenting. Teachers using this type of feedback said words or phrases to point out that the learner's response was all right. In most instances, the common words were 'good', 'very good', 'yes', 'correct' and 'ok.' In addition, it was shown that before the positive signs were provided, the teachers repeated the forms stated by the students. These forms can also be categorized as 'recasts' which included the teacher's reformulation of part or all of the students' statement (Flores et al., 2015). As Evans (2013) suggested, the "repetition of a speaker's utterance can be either a negative or a positive nature. By repetition here it was meant that the teacher was confirming the answers as well as showing interest in the content of the answer. Ellis (2009) and Le (2010) confirmed positive feedback was important as it functioned as an affective support to the learner and created motivation.

The teachers manifested some patterns that were in line with the "interactional feedback" which was defined as a strategy to expand or revise a student's answer (Han \& Hyland, 2015). For example, when the student was uncertain to continue by responding with an incomplete answer, the teacher stated extended information to complete the student's utterance. Providing such help was not considered as a negative feedback but rather facilitated the communication to be continuous and encouraged communicative language use in the classroom. It is because of this reason that this type of feedback is called interactional.

The teachers made use of corrective feedback too. Corrective (negative) feedback intended to correction of learners' errors (Evans, 2013). The teacher provided feedback on a student's utterance that contained an error. The feedback consisted of several forms: i) to specify the error, ii) to give the correct form, and iii) meta-linguistic information about the error. As Lewis (2002); Vermunt \& Donche (2017) further defined it, giving this kind of 
feedback gave an idea about learners' errors and directs them to improve. Evidently, it is encouraging to provide the students with the positive feedback but if extremely given, these forms may indicate that teachers have little confidence in their abilities (Tsiplakides \& Keramida, 2010).

Providing feedback can be very helpful to promote learning in the foreign language classroom. The purpose of this article was to examine with a CDA perspective, the feedback patterns used by a group of EFL teachers teaching advanced levels in CLT classrooms. Relating to the first research question, it was revealed that among feedback patterns, the teachers offered positive feedback (approving and repetition), interactional feedback and corrective (negative) feedback respectively. Based on the second research question of the study, the most frequent pattern of feedback employed by the teachers was the positive feedback; approving and repeating the students' response. Hence, CLT has been settled by the notion of positive feedback but these forms do not exclusively provide support for learning if excessively used. The praises and other forms of positive feedback should be balanced to the performance demonstrated by the students so that they could form influential learning strategies.

\section{Conclusions}

Examining the findings of the study would imply that teachers would need some guidelines that could serve as a basis for teacher feedback and reflection. Recurrently, many researchers have disagreed on matters such as whether to correct or not, what to correct, how to correct them and when to correct (Ellis, 2009; Le, 2010; Nunn, 2001; W, 2009). Through these insights, a comprehensive study is needed to provide some guidelines that could serve as a basis for teacher feedback and reflection because there are a variety of feedback types which the teacher can use, what is important is the appropriate choice of feedback on the basis of students' needs and the instructional activities.

Other aspects of classroom communication are as important such as student-initiated exchanges to provide teachers with a better understanding and awareness of their roles in improving students' thinking and learning as they give feedback to the students. Or else, attention should be directed to EFL teachers' ideologies in providing feedback to the students to uncover their philosophy of teaching and learning as a clue to detect their criteria in choosing some habits of providing feedback than others and hence to expand this area further. 


\section{Acknowledgments}

I would like to express my warm thankfulness to all the teachers and students who participated in this research.

\section{References}

Boud, D. (2000). Sustainable assessment: Rethinking assessment for the learning society. Studies in Continuing Education, 22(2), 151-167.

Ellis, R. (2009). Corrective feedback and teacher development. L2 Journal, 1, 1-18.

Evans, C. (2013). Making sense of assessment feedback in higher education. Review of Educational Research, 83(1), 70-120.

Fairclough, N. (1995). Critical Discourse Analysis: the Critical Study of Language. London: Longman.

Flores, A. M., Simao, A. M. V., Barons, A., \& Pereira, D. (2015). Perceptions of effectiveness, fairness and feedback of assessment methods: A study in higher education. Studies in Higher Education, 40(9), 1523-1534.

Han, Y., \& Hyland, F. (2015). Exploring learner engagement with written corrective feedback in a Chinese tertiary EFL classroom. Journal of Second Language Writing, 30, $31-44$.

Herschell, A. D., Greco, L. A., Filcheck, H. A., \& McNeil, C. . (2002). Who is testing who? Intervention in School and Clinic, 37(3), 140-148.

Konold, K.E., Miller, S.P., \& Konold, K. . (2004). Using teacher feedback to engage student learning. Teaching Exceptional Children, 36(6), 64-69.

Le, L. (2010). Teachers' immediate oral feedback in speaking lessons for 11th-form students. Lewis, M. (2002). Giving feedback in language classes. Singapore: SEAMEO Regional Language Center.

Nunn, R. (2001). Language learning across boundaries-negotiating classroom rituals.

Sinclair, J., \& Coulthard, M. (1992). Toward an analysis of discourse.' in M. Coulthard (Eds.). Advances in Spoken Discourse Analysis, 1-34.

Tsiplakides, I., \& Keramida, A. (2010). Promoting Positive Attitudes in ESL/EFL Classes. Internet TESL Journal, XVI(1).

Vermunt, J. D., \& Donche, V. (2017). A learning patterns perspective on student learning in higher education: State of the art and moving forward. Educational Psychology Review, 29(2), 269-299. 
W, Y. (2009). An Analysis of College English Classroom Discourse. Asian Social Science, $5(7), 152-159$.

Wodak, R., \& M, M. (2001). Methods in critical discourse analysis. London: Sage. 